San Jose State University

SJSU ScholarWorks

Master's Theses

Master's Theses and Graduate Research

Spring 2020

\title{
The Moderating Role of Emotional Intelligence on the Relationship Between Job Resources and Employee Engagement
}

Amanda Lipson

San Jose State University

Follow this and additional works at: https://scholarworks.sjsu.edu/etd_theses

\section{Recommended Citation}

Lipson, Amanda, "The Moderating Role of Emotional Intelligence on the Relationship Between Job Resources and Employee Engagement" (2020). Master's Theses. 5103.

DOI: https://doi.org/10.31979/etd.ghfv-62t4

https://scholarworks.sjsu.edu/etd_theses/5103

This Thesis is brought to you for free and open access by the Master's Theses and Graduate Research at SJSU ScholarWorks. It has been accepted for inclusion in Master's Theses by an authorized administrator of SJSU ScholarWorks. For more information, please contact scholarworks@sjsu.edu. 


\author{
A Thesis \\ Presented to \\ The Faculty of the Department of Psychology \\ San José State University \\ In Partial Fulfillment \\ of the Requirements for the Degree \\ Master of Science
}

by

Amanda Lipson

May 2020 
(C) 2020

Amanda Lipson

ALL RIGHTS RESERVED 
The Designated Thesis Committee Approves the Thesis Titled

THE MODERATING ROLE OF EMOTIONAL INTELLIGENCE ON THE RELATIONSHIP BETWEEN JOB RESOURCES AND EMPLOYEE ENGAGEMENT

by

Amanda Lipson

APPROVED FOR THE DEPARTMENT OF PSYCHOLOGY

SAN JOSÉ STATE UNIVERSITY

May 2020

Dr. Megumi Hosoda

Dr. Howard Tokunaga

Helene Fjagesund, M.S.
Department of Psychology

Department of Psychology

Consultant of People \& Organization, Capgemini Invent 


\begin{abstract}
THE MODERATING ROLE OF EMOTIONAL INTELLIGENCE ON THE RELATIONSHIP BETWEEN JOB RESOURCES AND EMPLOYEE ENGAGEMENT
\end{abstract}

\title{
By Amanda Lipson
}

The purpose of the current study was to examine the moderating role of emotional intelligence on the relationship between job resources (i.e., perceived supervisor support and autonomy) and employee engagement. Previous research has shown that these job resources are related to employee engagement. However, little attention has been paid to the possible moderators of this relationship. Therefore, this study aimed to bridge the gap in current literature by investigating how the relationship between job resources and engagement might change as a function of a personal resource (emotional intelligence). It was hypothesized that the positive relationship between job resources (perceived supervisor support and autonomy) and employee engagement would be stronger for employees with high emotional intelligence than for those with low emotional intelligence. A total of 125 employed individuals from various industries participated in an online survey. Consistent with the literature, both perceived supervisor support and autonomy had strong positive relationships with engagement. However, emotional intelligence did not moderate the relationship between supervisor support and autonomy and employee engagement. It is suggested that companies educate and train their leaders on the importance and practice of providing their employees with supervisor support and autonomy in the workplace. 


\section{ACKNOWLEDGMENTS}

First and foremost, I am forever grateful to my thesis chair, Dr. Megumi Hosoda for your endless patience, encouragement, kindness and expertise throughout this process. Your expert opinion and advice were second to none, and I am constantly amazed by your endless compassion and positivity. I always leave our conversations feeling revived and light-hearted, which I have come to find is a rare feeling during the thesis process. I would never have come close to finishing this if it weren't for you, so thank you so much. I would like to thank Dr. Howard Tokunaga for preparing me for this process, supporting me throughout the graduate program, and reading my papers with your meticulous eye. You care deeply for your students and push everyone to be the best version of themselves, and I thank you for doing this with me. I would also like to thank my third reader, Helene Fjagesund. Your extreme kindness, positivity, data-analytics expertise, and encouragement got me through one of the toughest parts of this process. You shine a light wherever you go, and even managed to shed brightness upon one of the most challenging processes of my life. I am forever thankful for your support and friendship.

I could not have done this without the support of my amazing parents. Mom and Dad, thank you for always having faith in me and being my biggest cheerleaders. I hope I've made you proud. To Stacey, my best friend, thank you for always believing in me even when I don't, I couldn't have asked for a better friend. Thank you to Reed who is always there with a joke to lighten the mood and for your motivational pep talks to cheer me on. Lastly, thank you to my amazing cohort - there's no one else I'd rather go through the grad school process with and I'm so happy to have you all in my life. 


\section{TABLE OF CONTENTS}

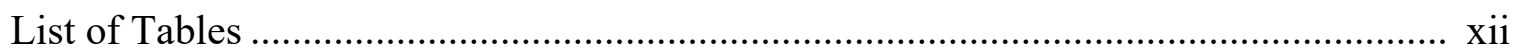

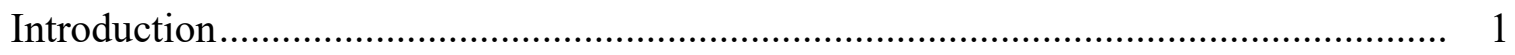

Definition of Employee Engagement................................................................. 3

The Job and Demands Resource (JD-R) Model ...................................................... 4

Relationship Between Job Resources and Employee Engagement ........................... 7

Perceived supervisor support .................................................................... 8

Autonomy ……………………………………............................... 10

Personal Resources as Moderators....................................................................... 12

Emotional Intelligence as a Moderator of the Relationship Between Job

Resources and Employee Engagement ............................................................ 13

The Current Study ............................................................................................... 19

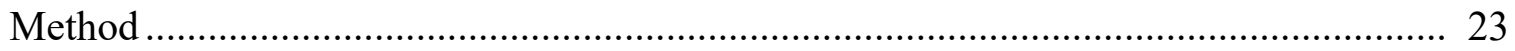

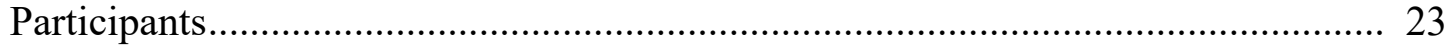

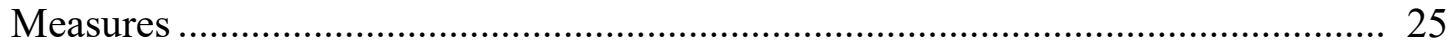

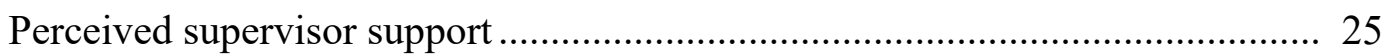

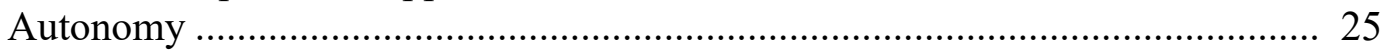

Emotional intelligence ........................................................................ 26

Employee engagement ............................................................................ 26

Demographic information............................................................................ 27

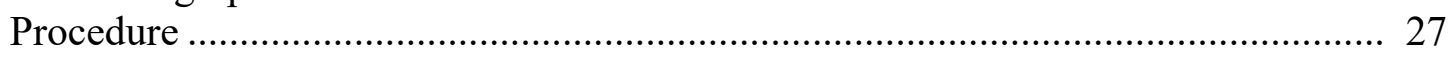

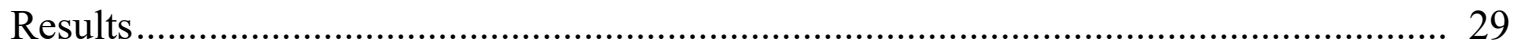

Descriptive Statistics and Pearson Correlations ………………………………...... 29

Tests of Hypotheses ………………………..................................................... 30

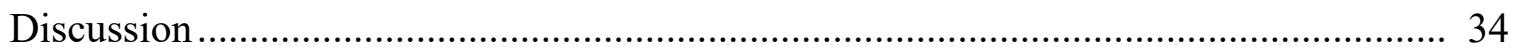

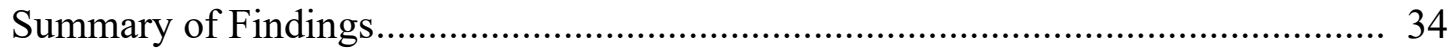

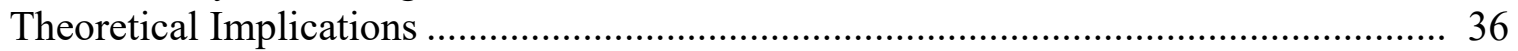

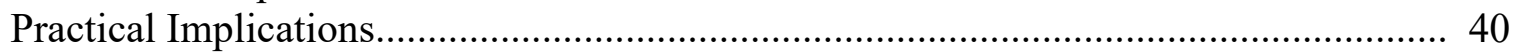

Strengths, Limitations, and Further Directions .......................................................... 41

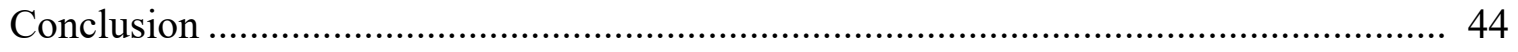

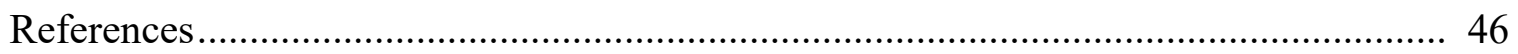

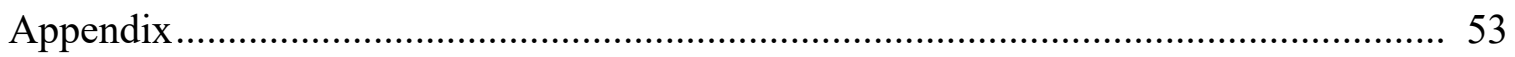

Demographic Questionnaire Items ................................................................... 53

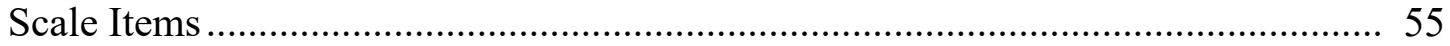




\section{LIST OF TABLES}

Table 1. Demographic Characteristics of Participants.....

Table 2. Descriptive Statistics; Pearson Correlations and Cronbach's Alpha Among Perceived Supervisor Support, Autonomy,

Emotional Intelligence, and Employee Engagement

Table 3. Hierarchical Multiple Regression Analysis for Perceived Supervisor Support, Emotional Intelligence, and Employee Engagement.

Table 4. Hierarchical Multiple Regression Analysis for Autonomy, Emotional Intelligence, and Employee Engagement 


\section{Introduction}

To survive and thrive successfully in today's volatile economic environment, organizations have to recruit and retain employees who will be committed, energetic, and enthusiastic in their work (Bakker \& Leiter, 2010). In other words, companies need to have engaged employees. Employee engagement is defined as a positive, fulfilling, work-related state of mind that is characterized by vigor, dedication, and absorption (Schaufeli, Salanova, Gonzalez-Roman \& Bakker, 2002). Employee engagement has been shown to be linked to both positive individual (e.g., in-role and extra-role performance, creativity, organizational commitment) (Bakker, Demerouti, Schaufeli \& Xanthopoulou, 2004, 2007) and business (e.g., sales growth, customer loyalty, financial performance of organizations) outcomes (Barbera, Macey, Schneider \& Young, 2009). Because of the positive outcomes associated with employee engagement, it has become an increasingly popular topic in the field of industrial and organizational psychology.

Despite its popularity, levels of engagement in the workplace are staggeringly low. For example, Gallup (2013) reported that only 13\% of employees around the globe were engaged in their jobs and that disengaged workers outnumbered their engaged counterparts at a rate of nearly 2 to 1 . In the United States, $70 \%$ of employees in the workforce were disengaged or actively disengaged in their jobs (Gallup, 2013). These staggering results might help to explain billions of dollars of financial costs for companies each year. Disengaged employees cost the American economy up to $\$ 550$ billion per year due to lost productivity (Sorenson \& Garman, 2013). On the other hand, according to Towers Perrin (2008), firms that had highly engaged employees had a 
spread of more than $5 \%$ in operating margin and 3\% in net margin compared to companies that had highly disengaged workers. Given the apparent desirability of having engaged employees and the negative ramifications of having disengaged employees, it is understandable that researchers have paid a considerable amount of attention to identifying antecedent conditions of employee engagement (Crawford, LePine, \& Rich, 2010).

The job demands and resource (JD-R) model (Bakker \& Demerouti, 2007) proposes that both job resources and personal resources predict employee engagement. Consistent with the model, research has shown that various job resources (e.g., autonomy, supervisor support, task significance, performance feedback) positively predict work engagement (Bakker et al. 2004).

Although various job resources have been shown to predict employee engagement, the effect of job resources on engagement might depend on individuals. That is, the relationship between job resources and engagement might be stronger for some individuals than for others. This is because some people are better able to recognize the availability of a job resource or utilize it to their benefit than others. However, the JD-R model seldom pays attention to the moderating role of personal resources on the relationship between job resources and employee engagement (Xanthopoulou, Bakker, Demerouti \& Schaufeli, 2007). Thus, the present study examines whether a personal resource moderates the relationship between job resources and engagement. More specifically, the present study examines if emotional intelligence, a personal resource 
(Lee \& Ok, 2012), moderates the relationship between two job resources (perceived supervisor support and autonomy) and employee engagement.

The following sections define employee engagement, introduce the JD-R model, and review literature on the relationships between job resources and engagement. Furthermore, emotional intelligence is introduced as a personal resource. I then explain how emotional intelligence moderates the relationship between job resources and engagement, and finally, the hypotheses that are tested in the present study are presented.

\section{Definition of Employee Engagement}

Employee engagement has been defined in several different ways. Kahn (1990) originally pioneered the concept of employee engagement and defined it as "the harnessing of organization members' selves to their work roles; in engagement, people employ and express themselves physically, cognitively, and emotionally during role performances" (p. 694). Maslach and Leiter (1997) characterized engagement as the direct opposite of burnout. For them, engagement refers to energy, involvement, and professional efficacy, which are considered to be the direct opposites of burnout dimensions (exhaustion, cynicism, and lack of professional efficacy).

Although Maslach, Schaufeli, and Leiter (2001) argued that engagement is the positive antipode to burnout; however, engagement is a separate and distinct concept from burnout. Consequently, Schaufeli, Salanova, Gonzalez-Roman, and Bakker (2002) defined engagement as a positive, fulfilling, work-related state of mind that is characterized by vigor, dedication, and absorption. Vigor refers to high levels of energy and psychological resilience while working, willingness to invest effort in a task, and 
persistence in difficult times. Dedication is characterized by a strong psychological involvement in one's work, combined with a sense of significance, enthusiasm, inspiration, pride, and challenge. Absorption refers to total concentration on and immersion in work, which is characterized by time passing quickly and finding it difficult to detach oneself from one's work. Absorption can be considered as a state of experience characterized by focused attention, clear mind, effortless concentration, loss of selfconsciousness, and intrinsic enjoyment (Csikszentmihalyi, 1990). Thus, engaged employees bring their personal energy to work, enthusiastically apply that energy to their work, and become absorbed in their work.

The present study uses the Schaufeli et al.'s (2002) definition because their definition is the most widely accepted definition of engagement. Furthermore, the Utrecht Work Engagement scale (Schaufeli et al., 2002), which is based on Schaufeli's conceptualization of engagement, has good reliability and validity as a measure of engagement, and has been used widely across many different countries.

\section{The Job Demands and Resource (JD-R) Model}

The JD-R model (Bakker \& Demerouti, 2007) has been used to explain employee engagement. The JD-R model posits that job characteristics can be divided into two broad categories: job demands and resources. Job demands refer to physical, psychological, social, or organizational aspects of the job that require sustained physical or psychological (cognitive and emotional) effort or skills, and are, therefore, associated with certain physiological or psychological costs. Examples of job demands are high pressure on the job, demanding interactions with supervisors, or emotionally demanding 
work. Job demands are not necessarily negative, but can become job stressors when meeting those demands exceeds the employee's adaptive capabilities (Bakker, Demerouti, \& Euwema, 2005).

The other category, job resources, refers to physical, social, or organizational aspects of a job that may reduce job demands and their associated physiological and psychological costs, assist in achieving work goals, or stimulate personal growth, learning, and development (Bakker \& Demerouti, 2007, 2004). Bakker and Schaufeli (2004) argued that employees should be provided with adequate physical, social, and organizational resources that enable them to reduce their job demands, be successful in their work role, and fuel their own personal development. Job resources may be located at organizational (e.g., career opportunities, job security, compensation), interpersonal and social relations (e.g., supervisor support, co-worker support), work (e.g., role clarity), and task levels (e.g., task significance, autonomy, performance feedback) (Bakker \& Schaufeli, 2004).

A more recent extension of the original JD-R model is the inclusion of personal resources (Xanthopoulou et al., 2007). Personal resources refer to aspects of the self that are generally linked to resiliency and the ability to successfully control and impact one's environment (Hobfoll, Ennis, Johnson, \& Jackson, 2003). Examples of personal resources include self-efficacy (an individual's perceptions of his or her ability to meet demands in a broad array of context) (Chen, Eden, \& Gully, 2001), organizational-based self-esteem ("the degree to which organizational members believe that they can satisfy their needs by participating in roles within the context of an organization") (Pierce, 
Gardner, Cummings \& Dunham, 1989, p. 625), and optimism (the tendency to believe that one will generally experience good outcomes in life) (Scheier \& Carver, 1985).

The JD-R model is a dual process model: the health impairment process and the motivational process. The health impairment process posits that high job demands lead to burnout, and consequently health problems (e.g., fatigue, sleeping problems, cardiovascular risks). For example, an employee who has straining emotional demands, heavy workload, or emotional dissonance in the workplace has been repeatedly found to suffer from exhaustion (one component of burnout) (Bakker, Demerouti, \& Schaufeli, 2003).

On the other hand, in the motivational process, job resources lead to work engagement which then leads to positive outcomes (e.g., organizational commitment, performance, intention to stay) (Bakker \& Demerouti, 2007). This is because job resources have both intrinsic motivational potential and extrinsic motivational potential. Job resources play an intrinsic motivational role because they foster employee's growth, learning and development (Bakker \& Demerouti, 2007) and help fulfill basic human needs (Deci \& Ryan, 2000) such as competence (White, 1959) and relatedness (Baumeister \& Leary, 1995). For example, social support from coworkers fosters a sense of belonging, which in turn leads to fulfilling the intrinsic need of relatedness. Job resources also play an extrinsic motivational role because they are likely to help employees meet their goals (Bakker \& Demerouti, 2007). According to the effortrecovery model (Meijman \& Mulder, 1998), work environments that offer a multitude of resources foster an employee's willingness and dedication to complete work tasks 
successfully to attain work goals. For example, a supervisor's feedback may increase the likelihood of being successful in achieving one's work goals. Regardless of whether job resources serve as either intrinsic or extrinsic motivational role, they lead to employee engagement, whereas their absence induces a pessimistic attitude towards work (Bakker $\&$ Demerouti, 2007).

\section{Relationship Between Job Resources and Employee Engagement}

Research shows that various job resources are positively related to employee engagement (Bakker \& Schaufeli, 2004; Barbier, Hansez, Chmiel \& Dermouti, 2013; Shuck et al, 2010). For example, in their meta-analysis, Crawford et al. (2014) found that job challenge, task variety, feedback, rewards and recognition, and development opportunities positively predicted engagement. That is, the more challenging employees' jobs were, the more tasks they used, the more feedback they were provided, the more rewards and recognition given, and the more development opportunities existed, the more engaged they became.

Barbier et al. (2013) found a positive relationship between opportunities for development and organizational support with employee engagement. Bakker and Schaufeli (2004) found that psychology safety, which was defined as the sense of being able to speak openly and do things without fear of losing reputation, status or career, was positively related to engagement. This means that if an individual feel psychologically safer, he or she is more likely to be engaged. Sarti (2014) studied the relationship between job resources and engagement among nurses. Job resources included learning 
opportunities, coworker support and supervisor support. Results showed that all of these job resources had a positive relationship with employee engagement.

All of these studies mentioned above demonstrate that the more job resources individuals have, the more engaged they will become. Although there are numerous job resources that have been found to yield positive outcomes, many of these resources (task variety, rewards, job challenges) could be considered as strategies that might incur additional financial burdens on organizations. For instance, task variety could incur more money for organizations because the more different tasks employees engage in, the more likely the organization will need to compensate for the more mundane tasks that are not being focused on. Resources like rewards and development opportunities also come with a financial burden to the company. On the other hand, supervisor support and autonomy are both cost effective and simple to institute within an organization; thus, this study focuses on these two job resources.

Perceived supervisor support. Perceived supervisor support is defined as "the degree to which employees perceive that supervisors offer employees support, encouragement and concern" (Babin \& Boles, 1996, p. 60). Perceived supervisor support may be determined by the amount of care supervisors provide to their employees, the degree to which they make employees feel valued, and the degree of concern they show for their employees' well-being (Cole, Bruch \& Vogel, 2006; Eisenberger, Stinglhamber, Vandenberghe \& Rhoades, 2002). According to the JD-R model, supervisor support is an important job resource that motivates employees to be engaged in their work. This is because intrinsically, perceived supervisor support induces a feeling of security amongst 
employees that their supervisor takes care of them (DeConinck, 2010). Extrinsically, supervisors who discuss learning goals, provide feedback, and help employees further develop skills increase the likelihood that their subordinates achieve their goals (Tharenou, 2001).

Perceived supervisor support has consistently been shown to be positively related to employee engagement (Bakker et al., 2004; Choo \& Nasurdin, 2016; Gagne \& Deci, 2005; Llorens et al. 2006; Othman \& Nasurdin, 2012; Schaufeli et al., 2008; Xanthopoulou et al., 2008). For example, Othman and Nasurdin (2012) found that when nurses in public hospitals perceived that their supervisors were supportive, showed concern for their feelings and needs, and provided help, information and constructive feedback, these nurses were more engaged in their work. Llorens et al. (2006) found similar results when they examined different occupations (e.g., customer service, bluecollar, white-collar, education, and human resources) in two countries (Netherlands and Spain). They found that resources, such as supervisor support, resulted in engagement among employees. Schaufeli and Bakker (2004) found a positive relationship between performance feedback, social support, and supervisory coaching with work engagement among four samples of Dutch employees at a telecommunication company.

Similar findings were obtained by Xanthopoulou et al. (2008). Forty-two employees from three branches of a Greek fast-food company completed a questionnaire and a daily journal over five consecutive workdays. The daily survey measured each person's levels of coaching and work engagement. Results showed that on days with coaching from supervisors, employees were more self-confident and more engaged than on days without 
coaching. Most importantly, there was evidence for a lagged effect of previous day's coaching on the next day's work engagement. Specifically, if a supervisor coached his or her subordinate on one particular day, the subordinate was more likely to be engaged on the following day.

Finally, Remo (2013) found that supervisory feedback predicted engagement. More specifically, he found that supervisors who implemented positive, constructive feedback to their subordinates had employees with higher levels of engagement at work. In sum, these results clearly show that perceived supervisor support is positively related to employee engagement.

Autonomy. Autonomy refers to the "degree to which the job provides substantial freedom, independence, and discretion to the employee in scheduling the work and in determining the procedures to be carrying it out" (Hackman \& Oldham, 1975, p. 162). Job autonomy sends employees strong signals that their managers have confidence in their skills and abilities to carry out tasks (Wang \& Netemeyer, 2002). Intrinsically, the more in control individuals feel regarding their work, the more motivated they are in the performance of that work. This fulfills individuals' innate need to feel like a personal agent in their environment and to experience a sense of control and efficacy in their actions (Deci \& Ryan, 2008). From an extrinsic motivational standpoint, employees with autonomy in the workplace are able to tailor their work procedures to their own strengths; thus, facilitating achievement of their work goals.

Research has consistently shown that autonomy is a key driver of engagement (Bakker \& Bal, 2010; Gagne \& Bhave, 2011; Halbesleben, 2010; Schaufeli et al., 
2009). For example, Schaufeli et al. (2009) conducted a two-wave longitudinal study with a 1-year interval on managers and executives at a Dutch telecom company. A 1-year follow-up was chosen because engagement was defined as a persistent psychological state that does not change in the short term (Schaufeli \& Salanova, 2007). During both the first and second wave of the study, participants completed a survey that measured autonomy and engagement. At Time 1, researchers found that autonomy predicted engagement positively. At Time 2, they found that an increase in autonomy between Time 1 and Time 2 predicted engagement at Time 2 positively, indicating that when job resources increased, work engagement also increased.

Similarly, Gagne and Bhave (2011) found that employees were more engaged when they were encouraged to participate in decision-making as to how their tasks would be carried out. These results are probably due to the fact if employees could choose tasks that are both interesting and personally meaningful to them, as well as choose their own strategies to address a situation, they are more likely to be engaged with their tasks. Halbesleben (2010) found that autonomy/job control significantly predicted engagement. Finally, Bakker and Bal (2010) also showed that autonomy was a predictor of engagement among 54 Dutch teachers. These teachers were asked to fill in a weekly questionnaire for five consecutive weeks which measured levels of autonomy, engagement, and job performance. Results showed that autonomy was positively related to weekly engagement, which in turn was related to weekly job performance (Bakker \& Bal, 2010). These studies provide strong support that autonomy is a driver of employee engagement. 


\section{Personal Resources as Moderators}

Judge et al. (1997) propose that personal resources may function as moderators of the relationship between environmental factors and organizational outcomes. Many studies (e.g., Bakker \& Demouti, 2007; Makikangas \& Kinnunen, 2003; Pierce \& Gardner, 2004; Prati, Pietrantoni, \& Cicognani, 2010) have examined personal resources as moderators of the relationship between unfavorable work characteristics and negative outcomes.

For example, Prati et al. (2010) examined self-efficacy (an individual's perceptions of his or her ability to meet demands in a broad array of context) (Chen, Eden \& Gully, 2001) as a moderator of the relationship between job demands (e.g., stress appraisal) and quality of life (e.g., burnout, compassion satisfaction, compassion fatigue) among rescue workers. Compassion satisfaction was defined as the pleasure the rescue workers derive from being able to help those who were experiencing traumatic stress and suffering (Stamm, 2010); and compassion fatigue was defined as emotional and physical erosion that takes place when helpers are unable to refuel and regenerate after helping those who were experiencing traumatic stress and suffering (Stamm, 2010).

They found that self-efficacy acted as a buffer in the relationship between stress appraisal and quality of life such that rescue workers with high self-efficacy were less affected by high-stress conditions in comparison with rescue workers with low selfefficacy. Rescue workers with high self-efficacy proactively coped with stressful life circumstances by believing they had the skills and resources to make it through the demanding situation. Therefore, having high self-efficacy reduced the impact of stress appraisal on workers' burnout, compassion dissatisfaction and compassion fatigue. 
Pierce and Gardner (2004) found that organizational-based self-efficacy (OBSE) buffered the effects of demanding conditions (e.g., organizational changes, role ambiguity) on depression, physical strain, and job satisfaction such that those with higher levels of OBSE experienced less depression and physical strain and more job satisfaction in the face of high job demands, compared to those with lower levels of OBSE.

Optimistic employees were also found to report lower levels of mental distress under demanding work conditions (e.g., time pressure, job insecurity, poor organizational climate) than their less optimistic coworkers (Makikangas \& Kinnunen, 2003). These studies suggest that employees with high levels of personal resources are better able to deal more effectively with demanding conditions, which in turn prevents negative outcomes (e.g., burnout, distress) (Bakker \& Demerouti, 2007).

Research indicates that personal resources buffer the negative effects of job demands on burnout. Alternatively, this may indicate that personal resources might amplify the positive effects of job resources on engagement. In other words, the relationship between job resources and engagement might be stronger for those with more personal resources compared to people with less personal resources. The next section provides a rationale for why personal resources enhance the relationship between job resources and engagement.

\section{Emotional Intelligence as a Moderator of the Relationship Between Job Resources and Employee Engagement}

More recently, emotional intelligence has been looked at as a personal resource (Lee \& Ok, 2012). Emotional intelligence can be defined as the ability of a person to understand and control their emotions, as well as recognize and manage those of others in their interpersonal relationships (Wong \& Law, 2002). Emotional intelligence is a 
multidimensional construct and can be examined in two different ways: ability emotional intelligence (Mayer \& Salovey, 1997) and trait emotional intelligence (Petrides \& Furnham, 2001). Salovey and Mayer (1990) introduced the concept of ability emotional intelligence as a type of social intelligence that speaks about the ability to monitor one's own and others' feelings to discriminate among them and to use this information to guide one's thinking and actions. Their ability emotional intelligence model consists of four dimensions: emotional perception (the ability to perceive emotions of the self and of others), emotional facilitation (the ability to generate, use, and feel emotions as needed to communicate feelings), emotional understanding (the ability to comprehend emotional information, understand how emotions combine and change over time, and the ability to appreciate emotional meanings), and emotional regulation (ability to remain open to feelings, and to monitor and regulate emotions to promote understanding and personal growth).

In contrast, Petrides and Furnhan (2001) proposed the concept of trait emotional intelligence, which views emotional intelligence as a constellation of emotional perceptions that are related to personality traits. Their definition of emotional intelligence allows for a continuum of responses that provides deeper insight into a person's emotional capacities and is broken into four dimensions: emotionality (ability to perceive and express emotions effectively and sustain close relationships), self-control (maintaining a healthy degree of control over urges and desires), sociability (ability to socially interact, clearly communicate and listen to others), and well-being (feeling positive, happy, and fulfilled). Those with high trait emotional intelligence perceive 
themselves as empathetic, self-confident, adaptable to different settings, self-motivated, socially skilled, and having good control, perceptions and expression of emotions (Petrides et al., 2016).

The present study uses trait emotional intelligence because this conceptualization takes into account self-perceptions and dispositions which are more in line with the everyday subjective nature of emotions. Trait emotional intelligence has also been found to predict well-being and health more strongly than ability emotional intelligence (Alvarez, 2016; Martins, Ramalho \& Morin, 2010). The components of trait emotional intelligence, specifically emotionality and self-control, align with the definition of personal resources, which refers to an individual's sense of ability to control and impact his or her environment (Hobfoll, 2002).

Emotional intelligence has been studied due to its numerous positive outcomes (Schutte \& Malouff, 2013). These outcomes include subjective well-being (Brackett \& Mayer, 2003; Brackett, Mayer, \& Warner, 2004; Schutte \& Malouff, 2011) and mental health (Martins et al., 2010; Schutte et al., 2007). Higher levels of emotional intelligence are also associated with a variety of interpersonal outcomes, including more cooperative behavior (Schutte et al., 2001), better interpersonal relationships (Lopes et al., 2004; Lopes et al., 2003), and higher relationship satisfaction (Lopes et al., 2003; Malouff et al., 2014). Individuals with higher emotional intelligence tend to perceive having more social support and are more satisfied with their social support (Austin et al., 2005; Gallagher \& Vella-Brodrick, 2008). From an organizational standpoint, results of meta-analyses showed that employees with higher emotional intelligence reported better work 
performance (O'Boyle, Humphrey, Pollack, Hawver \& Story, 2011) and tended to perform better in high emotional labor work (Joseph \& Newman, 2010). Further, more emotionally intelligent employees tended to show superior leadership (Harms \& Credé, 2010), including constructive conflict management (Schlaerth et al., 2013).

While emotional intelligence has not been examined as a moderator of perceived supervisor support and employee engagement relationship or autonomy and employee engagement relationship, there is indirect evidence that leads me to believe that emotional intelligence would be a moderator of these relationships. For example, Mahon, Taylor, and Boyatzis (2014) studied emotional intelligence as a moderator of the relationship between perceived organizational support, shared personal vision, and shared positive mood on engagement. They defined and measured emotional intelligence based on a behavioral approach that combines cognitive and affective abilities. According to them, emotional intelligence is the ability to be aware and knowledgeable of one's self and use that awareness to influence and manage one's behavior (Boyartzis, 2009). Perceived organizational support is defined as the general belief that one's organization values employees' contributions and cares about employees' well-beings (Saks, 2006). Shared personal vision is defined as positive emotions employees feel about the organization's view of the future and management's commitment to reach a particular, clearly defined vision or purpose (Boyatzis, 2008). Shared positive mood captures how employees feel about their work in the organization and the organization itself (Boyatzis, 2008). They believe that perceived organizational support, shared personal vision, and 
shared positive mood are constructs that assess how people feel about the organization and their role as organizational members.

They hypothesized that the relationship between perceived organizational support, shared personal vision, and shared positive mood with engagement would be stronger among those high in emotional intelligence than among those low in emotional intelligence. Mahon et al. (2013) argued that emotional intelligence would help employees obtain self-knowledge and effectively self-regulate to further relationships with others, as well as link themselves to their organizational role, which in turn would lead to engagement. Specifically, the self-management and self-awareness dimensions of emotional intelligence would work with psychological climate factors (e.g., perceived organizational support, shared personal vision) to activate an employee's ability to connect the self to his or her organization. Conversely, they believed that the absence of emotional intelligence could create issues for employees in terms of evolving selfknowledge and engaging in effective self-management. Lack of self-management and understanding of oneself would thwart the recognition and identification of available support that could hold great personal importance. The researchers summed up the point in saying, "If individuals don't know what they value and what goals are important to them, they are less likely to know if the organization they work for cares about their values and goals" (Mahon et al. 2019, p. 11).

Mahon et al.'s (2014) results indicated that emotional intelligence amplified the relationship between both perceived organizational support and engagement and the relationship between shared personal vision and engagement, such that when individuals 
had high emotional intelligence, perceived organizational support and shared personal vision were more strongly related to engagement levels as compared to individuals displaying lower emotional intelligence. They asserted that the self-management dimension of emotional intelligence allowed individuals to understand their personal vision and to assess the degree to which this vision was shared with that of the organization. That same dimension of emotional intelligence likely empowered individuals' self-management behaviors like emotional self-control to reconcile concerns about possible disconnects between their personal vision and their role as organizational members.

Additionally, they theorized the moderating effect of emotional intelligence on the relationship between perceived organizational support and engagement was because the self-knowledge building capability of emotional intelligence helped employees realize what type of support they wanted and needed from an organization. Without emotional intelligence, employees might struggle to understand and manage themselves effectively (e.g., decisions they make about their jobs and careers) enough to recognize what type of organizational support was most important to them. If individuals do not know what they value and what goals are important to them, they are less likely to know if the organization they work for cares about their values and goals. Therefore, through its selfknowledge building capability, emotional intelligence empowered employees to realize what type of support they wanted and needed from an organization; thus, allowing employees to connect their selves to their organization. 
Lastly, they argued that emotional intelligence did not moderate the shared positive mood and engagement relationship because mood was different from emotions, in that moods tended to elicit a wider range of cognitive and behavioral responses than did emotions because they were not targeted toward specific causes (Rhee \& Yoon, 2012). The scale items that measured shared positive mood focused on how employees felt about where they worked, whereas emotional intelligence focused on being aware of and managing specific emotions. Therefore, they believed that emotional intelligence might do very little to influence and diffuse different moods, specifically when mood was focused on where someone worked.

\section{The Current Study}

This study proposes that emotional intelligence acts as a moderator of the relationship between job resources (perceived supervisor support and autonomy) and employee engagement due to the emotionality, self-control, and sociability dimensions of emotional intelligence. There are a few reasons why it could be argued that emotional intelligence moderates the relationship between job resources (perceived supervisor support and autonomy) and engagement. Individuals high on emotional intelligence are versed at using and managing their emotions to achieve better workplace outcomes (Schutte \& Malouff, 2013); thus, it can be assumed that job resources like supervisor support and autonomy are adeptly recognized by such individuals. By recognizing these resources when they are available, employees can use these job resources to their fullest potential to accomplish their work tasks compared to those low on emotional intelligence. Furthermore, because those with high emotional intelligence have a greater sense of 
control over their work (Johnson, Batey, \& Holdsworth, 2009), job resources such as supervisor support and autonomy help them experience a greater sense of power, which fosters engagement.

The underlying mechanisms of the amplifying effect of emotional intelligence on the relationship between job resources and engagement are likely due to its emotionality and sociability dimensions. Additionally, while trait emotional intelligence does not include self-knowledge as a dimension, individuals with emotional intelligence become knowledgeable about themselves by monitoring their own emotions, as well as understanding others' emotions. Similar to Mahon et al.'s (2019) study, the selfknowledge building capability of emotional intelligence drives clarity and understanding of what type of support and resources employees want from their organization to become engaged. For example, employees who are individual contributors may desire to have a role in a leadership position one day. With the self-knowledge of their ultimate objective, they likely recognize that autonomy is necessary in their role to get them to the next step towards their goal. However, without emotional intelligence, they may not be aware of what they value and what goals are most important to them. If they do not know what they value, they are less likely to know if the organization they work for cares about their values and goals (Mahon et al. 2019).

Lastly, emotional intelligence may help individuals obtain self-knowledge and effectively self-regulate to further relationships with others; thus, internalizing and valuing resources such as supervisor support. The self-control dimension of emotional intelligence may enhance their assessment of their desired needs and to assess the degree 
to which those needs are being met. If there is a disconnect in what employees desire versus what they receive in the workplace, emotional intelligence enables self-control behaviors that help them reconcile concerns. To rectify the disconnect, the sociability dimension of emotional intelligence empowers individuals to clearly communicate necessary support or resources to activate engagement. On the other hand, those low in emotional intelligence are less likely to communicate their needs effectively; thus, weakening the job resources and engagement relationship.

Therefore, I hypothesize that emotional intelligence serves as a moderator in the job resources (perceived supervisor support and autonomy) and employee engagement relationship because it helps individuals gain better understanding and clarity of their self and external factors through its emotionality and sociability capabilities. By recognizing these resources, emotionally intelligent employees may utilize these job resources to their fullest potential to experience engagement in the workplace.

Although the aforementioned studies (Bakker \& Demouti, 2007; Makikangas \& Kinnunen, 2003; Pierce \& Gardner, 2004; Prati et al., 2010) have shed light on my understanding of potential moderating effects of personal resources, there is still a gap of knowledge pertaining to emotional intelligence as a moderator of the relationship between job resources and employee engagement. Therefore, the following hypotheses are tested.

Hypothesis 1: Emotional intelligence will moderate the positive relationship between perceived supervisor support and employee engagement such that the relationship 
will be stronger for employees with high emotional intelligence than for those with low emotional intelligence.

Hypothesis 2: Emotional intelligence will moderate the positive relationship between autonomy and employee engagement such that the relationship will be stronger for employees with high emotional intelligence than for those with low emotional intelligence.

The current study makes several contributions to the literature. While job resources have been positively related to employee engagement, the moderating role of personal resources in this relationship has seldom been studied. The present study examines the moderating effects of emotional intelligence on the relationship between job resources (e.g., perceived supervisor support, autonomy) and engagement. I hope to bridge the gap in current literature by better understanding how the relationship between job resources and engagement changes as a function of the levels of emotional intelligence. By examining and understanding this relationship, companies can optimize their resources to create the most effective engagement-inducing environment. 


\section{Method}

\section{Participants}

Data were collected through an online survey. More than 500 individuals from my personal social and working network were invited to participate in the study. Among them, 159 individuals responded, resulting in a response rate of $32 \%$. Participants who did not meet the criteria (i.e., being employed at the time of the survey and/or 18 years or older) or had a substantial amount of missing data were removed from further analysis. Thus, the final sample consisted of 125 participants.

The demographic information of participants is presented in Table 1. The participants' ages ranged from 18 years to 64 years old. The majority of them $(n=90$, $72.0 \%)$ were young, ranging from the age of 25 to 34 years, followed by $12.8 \%(n=16)$ who were 18 to 24 years. The majority of the sample was women $(n=91,72.8 \%)$ with $26.4 \%(n=33)$ being men. The majority of the sample identified themselves as White ( $n$ $=82,65.6 \%)$, followed by Asian or Pacific Islander $(n=25,20 \%)$, Black or African American $(n=1, .8 \%)$, Hispanic or Latin American $(n=9,7.2 \%)$ and "Other" $(n=8$, $6.4 \%)$

Participants worked in a variety of types of organizations, but most worked for-profit organizations $(n=81,65.3 \%)$. The majority of participants identified themselves as individual contributors $(n=74,59.8 \%)$, followed by managers $(n=36,29.0 \%)$, contractors $(n=7,5.6 \%)$, and "Other" $(n=7,5.6 \%)$. Organizational tenure among the sample was fairly short and $89.5 \%(n=111)$ of participants had been at their current companies for less than 5 years. 
Table 1

Demographic Characteristics of Participants

\begin{tabular}{|c|c|c|}
\hline Variable & $n$ & $\%$ \\
\hline \multicolumn{3}{|l|}{ Age } \\
\hline $18-24$ & 16 & 12.8 \\
\hline $25-34$ & 90 & 72.0 \\
\hline $35-44$ & 5 & 4.0 \\
\hline $45-54$ & 7 & 5.6 \\
\hline $55-64$ & 7 & 5.6 \\
\hline \multicolumn{3}{|l|}{ Gender } \\
\hline Female & 91 & 72.8 \\
\hline Male & 33 & 26.4 \\
\hline Other & 1 & .8 \\
\hline \multicolumn{3}{|l|}{ Race } \\
\hline White & 82 & 65.6 \\
\hline Asian or Pacific Islander & 25 & 20.0 \\
\hline Hispanic or Latin American & 9 & 7.2 \\
\hline Black or African American & 1 & .8 \\
\hline Other & 8 & 6.4 \\
\hline \multicolumn{3}{|l|}{ Organization Type } \\
\hline For-profit & 81 & 65.3 \\
\hline Health Care & 11 & 8.9 \\
\hline Education & 8 & 6.5 \\
\hline Non-profit & 7 & 5.6 \\
\hline Government & 4 & 3.2 \\
\hline Other & 13 & 10.5 \\
\hline \multicolumn{3}{|l|}{ Employment Type } \\
\hline Individual Contributor & 74 & 59.8 \\
\hline Manager & 36 & 29.0 \\
\hline Contractor & 7 & 5.6 \\
\hline Other & 7 & 5.6 \\
\hline \multicolumn{3}{|l|}{ Organizational Tenure } \\
\hline Less than 6 months & 15 & 12.1 \\
\hline 6 months -1 year & 24 & 19.4 \\
\hline $1-3$ years & 52 & 41.9 \\
\hline $3-5$ years & 20 & 16.1 \\
\hline $5-10$ years & 5 & 4.0 \\
\hline More than 10 years & 8 & 6.5 \\
\hline
\end{tabular}


Note. $N=125$

\section{Measures}

Perceived supervisor support. Perceived supervisor support was defined as "the degree to which employees perceive that supervisors offer employees support, encouragement and concern" (Babin \& Boles, 1996, p. 60). Perceived supervisor support was measured with nine items using a Perceived Supervisor Support scale developed by Eisenberger et al. (2002). Examples of the items were "My manager fosters genuine and trusting relationships on the team" and "My manager rewards me in a manner that makes me feel valued." The scale items were measured using a 7-point Likert scale $(1=$ Strongly Disagree, 7 = Strongly Agree). Responses to these items were averaged to create a perceived supervisor support score. Higher scores indicated higher levels of perceived supervisor support. Cronbach's $\alpha$ was .91 , indicating high internal consistency of the scale.

Autonomy. Autonomy was defined as the degree to which the job provides freedom, independence, and discretion to the employee in scheduling the work and in determining the procedures to be carrying it out (Hackman \& Oldham, 1975). Autonomy was measured by eight items developed from the Maastrict Personal Autonomy Questionnaire (Mars et al., 2014) and consisted of questions such as "I am allowed to decide how to go about getting my job done (the methods I use)" and "I have some control over the sequencing of my work activities (when I do what)." The items were measured using a 7point Likert scale $(1=$ Strongly Disagree, $7=$ Strongly Agree $)$. Responses to these items 
were averaged to create an autonomy score. Higher scores indicated higher levels of job autonomy. Cronbach's $\alpha$ was .91 , indicating high reliability.

Emotional intelligence. Emotional intelligence was defined using Petrides and Furnhan's (2001) trait emotional intelligence definition that is broken into four dimensions: emotionality (ability to perceive and express emotions effectively and sustain close relationships), self-control (maintaining a healthy degree of control over urges and desires), sociability (ability to socially interact, clearly communicate and listen to others), and well-being (feeling positive, happy, and fulfilled). Trait emotional intelligence was measured using the 30-item Trait Emotional Intelligence-Short Form (Cooper \& Petrides, 2010), which has been designed to measure global trait emotional intelligence. Examples of the items were "Expressing my problems with words is not a problem for me" and "I can deal effectively with people." The items were measured using a 7-point Likert scale $(1=$ Strongly Disagree, $7=$ Strongly Agree $)$. Responses to these items were averaged to create an emotional intelligence score. Higher scores indicated higher levels of emotional intelligence. Cronbach's $\alpha$ was .88 , indicating high internal consistency of the scale.

Employee engagement. Employee engagement was defined as positive fulfilling, work-related state of mind that is characterized by vigor, dedication, and absorption (Bakker et al., 2002). Employee engagement was measured using the Utrecht Work Engagement 17-item scale (Schaufeli \& Bakker, 2004) that assesses the three components with items such as "At my work, I feel bursting with energy" to assess vigor, "I am immersed in my work" which measures absorption, and "I am proud of the work 
that I do" which measures dedication. The scale items were measured using a 7-point Likert scale $(1=$ Strongly Disagree, $7=$ Strongly Agree $)$. Responses to these items were averaged to create an engagement score. Higher scores among employees indicated higher levels of work engagement. Cronbach's $\alpha$ was .90 for the aggregated scale, indicating high internal consistency.

Demographic information. Participants were also asked to respond to questions regarding their demographic information. The questions asked about age, gender, organization type, employment type, and organizational tenure.

\section{Procedure}

Data were collected online via Qualtrics, an online survey platform. Employees from various industries and backgrounds received an email invitation to participate in the survey through two social media platforms: Facebook and LinkedIn. Following the original post inviting individuals to participate, approximately three individuals shared the survey with their networks, allowing for data collection to reach beyond my personal network of connections.

The invitation contained a brief message detailing the purpose of the study, a short description of the nature of the study, and a link to the survey. Participants who clicked the link were directed to a consent form. The consent form stated the purpose of the study which was to investigate how situational factors and individual factors influence people's behavior in the workplace. The consent form also included who to contact with any questions, information about the risks and the benefits of the study, and the anonymous voluntary nature of the survey. When participants clicked the button "I consent, continue 
with survey," participants indicated their willingness to proceed with completing the survey. Participants who selected the option "I do not consent, exit survey" were taken directly to the end of the survey and thanked for their participation. An unsigned consent notice was deemed appropriate due to the anonymous nature of the study and minimal risk involved. Participants had the ability to start and stop the survey freely and the option to end and exit the survey at any time. After the survey was completed, they were thanked for their participation and Qualitrics automatically exited them from the survey. All responses were logged in Qualtrics.

Once data were collected, they were analyzed using the Statistical Package for the Social Sciences (SPSS 25 Version) program. Data were analyzed using Pearson correlations and hierarchical multiple regression analyses 


\section{Results}

\section{Descriptive Statistics and Pearson Correlations}

Table 2 displays the descriptive statistics of the measured variables and Pearson correlations among them. On average, participants perceived relatively high levels of supervisor support $(M=5.46, S D=1.06)$, indicating that they thought that their supervisors showed care, encouragement and concern for their well-being. Participants also reported that they had high levels of autonomy in the workplace $(M=5.23, S D=$ $1.15)$ and that they were highly engaged at work $(M=4.84, S D=.93)$, meaning that they felt freedom and discretion in determining the procedures to carry out their work and were immersed, energetic, and involved in their work, respectively. Finally, participants rated themselves as having a high sense of emotional intelligence $(\mathrm{M}=5.30, S D=.63)$, indicating that they believed they had the ability to understand and control their emotions as well as recognize those of others in their relationships.

Table 2

Descriptive Statistics, Pearson Correlations, and Cronbach's Alpha Among Perceived Supervisor Support, Autonomy, Emotional Intelligence and Employee Engagement

$\begin{array}{lllllll}\text { Variable } & M & S D & 1 & 2 & 3 & 4\end{array}$

\begin{tabular}{|c|c|c|c|c|c|c|}
\hline 1. Perceived Supervisor Support & 5.46 & 1.06 & $(.91)$ & & & \\
\hline 2. Autonomy & 5.23 & 1.15 & $.42 * *$ & $(.91)$ & & \\
\hline 3. Emotional Intelligence & 5.30 & .63 & .13 & .07 & $(.88)$ & \\
\hline 4. Employee Engagement & 4.84 & .93 & $.39 * *$ & $.27 * *$ & $.22 *$ & $(.90)$ \\
\hline
\end{tabular}


Results of the Pearson correlations showed a significant positive relationship between perceived supervisor support and autonomy $r(123)=.42, \mathrm{p}<.001$, meaning that the more participants felt that their supervisors offered support and guidance, the more they felt their job provided significant freedom and independence. Perceived supervisor support was also positively related to employee engagement, $r(123)=.39, p<.01$, indicating that the more participants felt their supervisors offered encouragement and showed their appreciation, the more positive, absorbed and energetic they felt with their work. There was also a significant and positive relationship between autonomy and employee engagement, $r(123)=.27, p<.01$, such that the more participants experienced having independence and discretion in carrying out their tasks in their roles, the more dedicated,

focused, and enthusiastic they felt about their work. There was a significant and positive relationship between emotional intelligence and employee engagement, $r(123)=.22, p<$ .05 , such that the higher the participants rated their ability to recognize and manage emotions, the more inspired and energetic they were in their work. Interestingly, emotional intelligence was not significantly related to perceived supervisor support, $r(123)=.13, p>.05$ or autonomy, $r(123)=.07, p>.05$.

\section{Tests of Hypotheses}

A hierarchical multiple regression correlation (MRC) analysis was used to test the study's hypotheses. Hypothesis 1 stated that emotional intelligence would moderate the positive relationship between perceived supervisor support and employee engagement such that the relationship would be stronger for employees with high emotional intelligence than for those with low emotional intelligence. For this MRC analysis, three 
steps were used. Perceived supervisor support was entered into the first step. The moderator variable of emotional intelligence was entered in the second step. Lastly, the cross-product of perceived supervisor support and emotional intelligence was entered in the third step to test the moderating effect. Results of the analysis are shown in Table 3. Table 3

Hierarchical Multiple Regression Analysis for Perceived Supervisor Support, Emotional Intelligence, and Employee Engagement

\begin{tabular}{lccc}
\hline \multicolumn{1}{c}{ Predictor } & \multicolumn{1}{c}{$R^{2}$} & \multicolumn{1}{c}{$\Delta R^{2}$} \\
\hline 1. Perceived Supervisor Support & $.39^{* * *}$ & $.15^{* * *}$ & $.15^{* *}$ \\
2. Emotional Intelligence (EI) & $.22^{* *}$ & $.18^{* *}$ & $.03^{* *}$ \\
$\begin{array}{l}\text { 3. Perceived Supervisor } \\
\quad \text { Support } \mathrm{x} \text { EI }\end{array}$ & $.18^{* *}$ & .01 \\
\hline Note: $N=125{ }^{*} \mathrm{p}<.05^{* *} \mathrm{p}<.01$. &
\end{tabular}

Results from the first step of the analysis showed that perceived supervisor support accounted for $15 \%$ of the variance in employee engagement, $R^{2}=.15, F(1,119)=20.69$, $p<.001$. This means that perceived supervisor support significantly contributed to the prediction of participants' engagement. In the second step, emotional intelligence accounted for an additional 3\% of variance in employee engagement above and beyond the effect of perceived supervisor support, $\Delta R^{2}=.03, \Delta F=(1,118)=3.97, p<.05$. This indicates that emotional intelligence predicted participants' engagement above and beyond the effect of perceived supervisor support. Results of the third step showed that the incremental effect of the interaction of perceived supervisor support and emotional intelligence was not significant and only accounted for an additional $1 \%$ of variance in 
employee engagement above and beyond the effects of perceived supervisor support and emotional intelligence, $\Delta R^{2}=.01, F(1,117)=.82, p>.05$. This suggests that emotional intelligence did not moderate the relationship between perceived supervisor support and employee engagement. These results did not show support for Hypothesis 1.

Hypothesis 2 stated that emotional intelligence would moderate the positive relationship between autonomy and employee engagement such that the relationship would be stronger for employees with high emotional intelligence than for those with low emotional intelligence. For the second MRC analysis, three steps were also used. Autonomy was entered into the first step. The moderator variable of emotional intelligence was entered in the second step. Lastly, the cross-product of autonomy and emotional intelligence was entered in the third step to test the moderating effect. Results of the analysis are shown in Table 4.

Table 4

Hierarchical Multiple Regression Analysis for Autonomy, Emotional Intelligence, and Employee Engagement

\begin{tabular}{|c|c|c|c|}
\hline Predictor & & $R^{2}$ & $\Delta R^{2}$ \\
\hline 1. Autonomy & $.27 * *$ & $.07 * * *$ & $.07 * *$ \\
\hline 2. Emotional Intelligence (EI) & .07 & $.11^{* *}$ & $.04^{* *}$ \\
\hline 3. Autonomy x EI & & $.12 * *$ & .01 \\
\hline
\end{tabular}

Note: $N=125 .{ }^{*} \mathrm{p}<.05 * * \mathrm{p}<.01$

Results from the first step of the analysis showed that autonomy accounted for $7 \%$ of the variance in employee engagement, $R^{2}=.07, F(1,119)=9.19, p<.01$. This means that 
autonomy significantly contributed to the prediction of participants' engagement. In the second step, emotional intelligence accounted for an additional $4 \%$ of variance in employee engagement above and beyond the effect of autonomy, $\Delta R^{2}=.04, \Delta F=(1,118)$ $=5.15, p<.05$. This indicates that emotional intelligence predicted participants' engagement above and beyond the effect of autonomy. Results of the third step showed that the incremental effect of the interaction of emotional intelligence and autonomy was not significant and only accounted for an additional $1 \%$ of the variance in engagement above and beyond the effects of autonomy and emotional intelligence, $\Delta R^{2}=.01, F(1$, $117)=.85, p>.05$. This suggests that emotional intelligence did not moderate the relationship between perceived supervisor support and employee engagement. These results show that Hypothesis 2 was not supported. 


\section{Discussion}

Employee engagement has become a popular and important topic as it has been shown to be linked to many positive individual (e.g., in-role and extra-role performance, creativity, organizational commitment) (Bakker et al. 2004; Bakker et al. 2007) and business (e.g., sales growth, customer loyalty, financial performance) outcomes (Barbera et al. 2009). As employee engagement becomes increasingly popular, research has focused on identifying predictors of employee engagement and understanding whether these predictors can increase and sustain employee engagement in the workforce.

Research has shown that various job resources (e.g., supervisor support, autonomy, rewards) predict employee engagement (Bakker \& Schaufeli, 2004; Barbier, Hansez, Chmiel \& Dermouti, 2013; Shuck et al, 2010). However, several researchers have argued that the relationships between job resources and employee engagement might vary based on individuals (Judge et al., 1997). These individual differences stem from personal resources (e.g., emotional intelligence, self-efficacy, optimism). This study examined if emotional intelligence, a personal resource (Lee \& Ok, 2012), moderates the relationship between two job resources (autonomy and perceived supervisor support) and employee engagement.

\section{Summary of Findings}

Hypothesis 1 stated that emotional intelligence would moderate the positive relationship between supervisor support and employee engagement such that the relationship would be stronger for employees with high emotional intelligence than for those with low emotional intelligence. Results showed that emotional intelligence did not 
moderate the relationship between perceived supervisor support and employee engagement, but supervisor support positively predicted engagement; thus, Hypothesis 1 was not supported. A potential reason that emotional intelligence did not moderate the relationship between perceived supervisor support and employee engagement might be because those individuals who perceived their supervisors to be supportive had already received regular feedback from their supervisor and had the proper guidance to achieve their goals. Therefore, emotional intelligence was not needed to motivate them further; thus making emotional recognition and management unnecessary to evoke further engagement. Consequently, supervisor support increased employee engagement, regardless of their levels of emotional intelligence.

Hypothesis 2 stated that emotional intelligence would moderate the positive relationship between autonomy and employee engagement such that the relationship would be stronger for employees with high emotional intelligence than for those with low emotional intelligence. Results showed that emotional intelligence did not moderate the relationship between autonomy and employee engagement, but autonomy positively predicted employee engagement; thus, Hypothesis 2 was not supported. One potential reason that emotional intelligence did not moderate this relationship could be because emotional intelligence may pertain to recognizing and understanding one's and others' emotions. This would indicate that if a job resource, such as autonomy, lacks an emotional or personal component, the ability to recognize such a resource would not work. 
Another potential reason for the lack of emotional intelligence as a moderator for either hypothesis may be because self-reporting of emotional intelligence was inaccurate for this sample. Emotional intelligence ratings were based on individuals' evaluation of themselves, which would require respondents to not only have good insight into their own minds, but to be honest about their thoughts and feelings. This sample might have viewed themselves more favorably, creating higher emotional intelligence scores that were not necessarily representative of their true emotional intelligence levels. Therefore, the measure of emotional intelligence in this study might have held biases which could have distorted results. However, this interpretation is speculative.

Although results did not show emotional intelligence as a moderator of the relationship between perceived supervisor support or autonomy and employee engagement, they showed that perceived supervisor support, autonomy, and emotional intelligence were all positively related to employee engagement at work. These results indicate that the more support they received from their supervisors, the more autonomy employees had, and the more emotionally intelligent they were, the more engaged they were in their work.

\section{Theoretical Implications}

This study's results add to the existing literature on the relationship between perceived supervisor support and employee engagement (Bakker et al., 2004; Choo \& Nasurdin, 2016; Gagne \& Deci, 2005; Llorens et al. 2006; Othman \& Nasurdin, 2012; Remo 2013; Schaufeli et al., 2008; Xanthopoulou et al., 2008), as well as autonomy and employee engagement (Bakker \& Bal, 2010; Gagne \& Bhave, 2011; Halbesleben, 2010; 
Schaufeli et al., 2009). Consistent with the JD-R model's motivational process, the results of the present study showed that when employees were provided with job resources of supervisor support and autonomy, they were likely to feel engaged. This may be because extrinsically, these resources help employees meet their goals (Bakker \& Demerouti, 2007). For example, employees who receive regular feedback from their supervisors may feel more supported and have the proper guidance to help them achieve their objectives. This may also be because intrinsically, supervisor support and autonomy foster an employee's growth, learning and development (Bakker \& Demerouti, 2007), and help fulfill basic human needs (Deci \& Ryan, 2000) such as competence (White, 1959) and relatedness (Baumeister \& Leary, 1995). For example, a supervisor's support may foster a sense of belonging, which in turn leads to fulfilling the intrinsic need of relatedness. Individuals who experience autonomy in their role may be intrinsically motivated because their innate need to feel like a personal agent in one's environment and to experience a sense of control and efficacy in one's actions is met (Deci \& Ryan, 2008). Additionally, the more in control individuals feel regarding their work, the more motivated they are in the performance of that work (Deci \& Ryan, 2008). Regardless of whether supervisor support and autonomy serve as either intrinsic or extrinsic motivators, this study supports that they lead to employee engagement.

There is very little research on the relationship between emotional intelligence and employee engagement; thus, making this one of the first studies to discover its positive relationship. Results of the present study indicate that emotional intelligence is a personal resource that predicts employee engagement. This study is also one of the first 
that examined emotional intelligence as a moderator of the relationship between job resources and employee engagement. Most previous studies on emotional intelligence have only explored its role as an independent or dependent variable. An exception to this is Mahon et al. (2019), who found that emotional intelligence moderated the relationship between perceived organization support and engagement, as well as the relationship between shared personal vision and engagement. They attributed this moderating effect of emotional intelligence to the greater clarity and understanding of resources an individual with high emotional intelligence might have. They believed that those with high emotional intelligence had greater clarity and understanding of resources, which allowed them to internalize and value these resources, and that would then lead to more engagement compared to those with low emotional intelligence. They also argued that emotional intelligence helped employees realize what type of support they wanted and needed from an organization.

However, this present study's results revealed that emotional intelligence did not necessarily amplify the perceived supervisor support and employee engagement relationship, nor the autonomy and employee engagement relationship. These different results may be due to the different measures of emotional intelligence between their study and my study. Mahon et al.'s emotional intelligence scale had over 70 questions that did not look at trait emotional intelligence specifically, but combined adaptability/positive outlook, achievement orientation, and emotional self-control to form a measure of emotional intelligence. Additionally, the emotional intelligence levels of their respondents were measured by multiple raters, including their manager(s), peers and 
subordinates. Therefore, the nature of this multi-rater assessment might have delivered more accurate results because raters might be able to evaluate emotional intelligence more accurately since there were no social desires driving the raters to score more favorably. Peer evaluations might be more representative of the individual's true emotional intelligence levels, rather than idealistic and socially-driven emotional intelligence scores that self-reports may induce.

In contrast, this study's scale had 30 trait emotional intelligence questions which focused on four components: emotionality (ability to perceive and express emotions effectively and sustain close relationships), self-control (maintaining a healthy degree of control over urges and desires), sociability (ability to socially interact, clearly communicate and listen to others), and well-being (feeling positive, happy, and fulfilled) (Petrides \& Furnhan, 2001). While there is some overlap between scales, the measure of emotional intelligence differed, making the results of the two studies less comparable. The nature of this survey was self-report only; therefore, responses were based on each individual's self-perception. This leads to further questions on the best scale to measure emotional intelligence, as well as the accuracy of having self-report versus multi-rater reports.

Additionally, the nature of the samples may account for the differing results. Half of their sample consisted of not-for-profit educational institution employees, whereas this study's sample lacked employees from the education sector. These differing results instigate further questions on whether emotional intelligence may moderate the relationship between particular job resources and employee engagement. Perhaps 
individuals with high emotional intelligence are able to recognize the availability of some job resources, but not all resources. Thus, emotional intelligence may act as a moderator of the relationship between only some job resources and employee engagement.

\section{Practical Implications}

The practical implications of the results of this study are geared towards organizations seeking to foster employee engagement. The JD-R model highlights the importance of job resources as predictors of engagement (Bakker \& Demerouti, 2007); and given the results of this study, it is critical to educate and train company leaders on providing their employees with supervisory support and autonomy in the workplace.

One way managers can ensure that they are showing support for their subordinates would be to have regularly held one-on-one meetings. During these one-on-ones, supervisors can show their support by discussing employee goals, both within their existing roles and their overarching career-oriented goals. By understanding the direction employees want to take their careers, managers can help employees develop skills to guide them on the right path to attain their goals. Additionally, it is important for supervisors to thank employees for their hard work. When employees receive gratitude and acknowledgement from their supervisors, they feel valued and secure in their role (DeConinck, 2010).

Education and training could be done in several ways to provide employees more autonomy, but managers should frequently ask for their employees' opinions and let them design their processes when available. By allowing them freedom and discretion in scheduling out their work and determining the procedures to carry it out, managers send 
strong signals that they have confidence in their employees' skills and abilities (Wang \& Netemeyer, 2002). In turn, employees may be able to execute on their tasks more effectively since they are able to customize their procedures to their own strengths; thus, enabling attainment of work goals.

This study's results indicate that those who are emotionally intelligent are engaged in the workplace. To attract emotionally intelligent candidates, companies should try and implement interview questions that focus on emotional intelligence. Training interviewees on how to gauge responses to these questions may help with recruiting efforts and could lead to a more engaged workforce. Interviewees could be educated on the dimensions of emotional intelligence and trained on what kind of responses or behaviors from the candidate show proven self-control or understanding of others' emotions. Having specific questions for interviewees to ask, like how a candidate behaved in a specific situation, may also provide insight on that person's level of emotional intelligence.

\section{Strengths, Limitations, and Further Directions}

The current study has several strengths. To begin with, this was one of the first to examine emotional intelligence as a moderator of the relationship between job resources and employee engagement. This is a strength because most studies on emotional intelligence have only examined its role as an independent or dependent variable, and as it becomes more popularized, it is important to have a deeper understanding of the concept. 
Very limited research has been conducted on the relationship between emotional intelligence and employee engagement. This is one of the first studies to examine the relationship, and the results indicate that emotional intelligence has a positive relationship with employee engagement. This information might be applicable for recruitment and retention purposes.

In addition to strengths, the current study also has some limitations. First, the use of self-report surveys may not be the most accurate method of collecting accurate information about emotional intelligence. For example, people might have reported their answers based on what they believed is the "correct" or socially acceptable way to answer question about themselves, thus altering data. Therefore, it is difficult to determine the extent to which the information provided by the respondents was accurate or if they responded based on what they believed was most socially acceptable or desired. These self-reported responses may be a more accurate representation of idealistic ways individuals perceive themselves than an accurate representation of their actual emotional intelligence levels. If this study were to be repeated, I would implement a multi-rater system where participants' peers also rate their emotional intelligence. Allowing for peer reviews could capture more accurate responses by mitigating the desire to respond in a socially desirable manner.

Next, there was a lack of variability in the demographics of this study, specifically ethnicity, gender and organization type. The sample was fairly homogenous with most of the individuals identifying as Caucasian, female and working in for-profit organizations. Because men and different ethnicities may have been underrepresented in the sample, 
results may have been skewed. The lack of diversity makes it difficult to generalize the present results to a larger population and different types of organizations besides forprofit organizations. If this study were repeated, I would target other organization types, like non-profits and those in the educational sector, and ask that their employee base respond to this survey. Additionally, I would seek out diversity and inclusion groups and ask for their participation in this study, as well as the request to send the survey to their networks in order to increase the generalizability of findings.

It would be beneficial for future research to explore the moderating effect of emotional intelligence on other relationship. Though the results of this study did not yield statistical significance, emotional intelligence has been found to be a moderator of other resources and employee engagement (Mahon et al. 2019). Because existing studies' results of emotional intelligence as a moderator have been conflicting, further examination of its interaction effect between other resources such as co-worker support, perceived organizational support, shared positive mood, shared personal vision and employee engagement would be interesting. Co-worker support would be a good job resource to study since it involves emotional understanding and processing of one's and others' emotions and behaviors. Perceived organization support, shared positive mood, and shared personal vision would be good resources to examine as they would allow for the Mahon et al.'s study (2019) to be repeated, with the main difference being that trait emotional intelligence would be used as a moderator opposed to the emotional intelligence construct they examined. It would also be important to study other job 
resources to understand why emotional intelligence may moderate the relationship between some job resources and employee engagement, yet not others.

Future research should strive to explore different measures of emotional intelligence, such as ability emotional intelligence which consists of four dimensions: emotional perception (the ability to perceive emotions of the self and of others), emotional facilitation (the ability to generate, use, and feel emotions as needed to communicate feelings), emotional understanding (the ability to comprehend emotional information, understand how emotions combine and change over time, and the ability to appreciate emotional meanings), and emotional regulation (ability to remain open to feelings, and to monitor and regulate emotions to promote understanding and personal growth) (Salovey $\&$ Mayer, 1990). Measuring ability emotional intelligence is more costly and timeconsuming as it must be done in person and there are "correct" and "not correct" answers. However, as emotional intelligence continues to gain popularity, it becomes increasingly important to understand how to study and measure this concept.

Lastly, it may be advantageous for future research to examine the moderating role of other personal resources (self-esteem, optimism, resilience) and how they affect the relationship between job resources and employee engagement. Because job resources are positively related to employee engagement, it is beneficial for organizations to understand how they can further leverage job resources to create an engaged workforce

\section{Conclusion}

The goal of the current study was to examine if emotional intelligence moderated the relationship between two job resources (perceived supervisor support and autonomy) and 
employee engagement. The study found that employees who had supervisor support and/or autonomy were engaged in the workplace. The study also found that those who had high emotional intelligence were engaged as well. The study did not find emotional intelligence as a moderator, suggesting that this was not a personal resource that influences the relationship between perceived supervisor support, autonomy, employee engagement. Thus, organizations may use this to educate and train their leaders on the importance of showing support and providing autonomy to their direct reports. This may help direct future researchers continue to look at how other personal resources can be leveraged to enhance the job resources and engagement relationship. 


\section{References}

Babin, B. J. \& Boles, J. S. (1996). The effects of perceived co-worker involvement and supervisor support on service provider role stress, performance and job satisfaction. Journal of Retailing, 72, 57-75. doi: 10.1016/s0022-4359(96)90005-6

Bakker, A.B. and Bal, M.P. (2010), Weekly work engagement and performance: A study among starting teachers. Journal of Occupational and Organizational Psychology, 83, 189-206. doi: 10.1348/096317909X402596

Bakker, A.B. \& Demerouti, E. (2007). The job demands-resources model: State of the art. Journal of Managerial Psychology, 22, 309-328. doi: 10.1108/02683940710733115

Bakker, A. B., Demerouti, E., \& Euwema, M. C. (2005). Job resources buffer the impact of job demands on burnout. Journal of Occupational Health Psychology, 10, 170180. doi: $10.1037 / 1076-8998 \cdot 10.2 .170$

Bakker, A. B., Demerouti, E., Taris, T. W., Schaufeli, W. B., \& Schreurs, P. J. (2003). A multigroup analysis of the job demands-resources model in four home care organizations. International Journal of Stress Management, 10, 16-38. doi: $10.1037 / 1072-5245.10 .1 .16$

Barbier, M., Hansez, I., Chmiel, N., \& Demerouti, E. (2013). Performance expectations, personal resources, and job resources: How do they predict work engagement? European Journal of Work and Organizational Psychology, 22, 750-762. doi: 10.1080/1359432X.2012.704675

Baumeister, R. F., \& Leary, M. R. (1995). The need to belong: Desire for interpersonal attachments as a fundamental human motivation. Psychological Bulletin, 117, 497529. doi: 10.1037/0033-2909.117.3.497

Boyatzis, R. E. (2008). Leadership development from a complexity perspective. Consulting Psychology Journal: Practice and Research, 60, 298313. doi: $10.1037 / 1065-9293.60 .4 .298$

Brackett, M. A. \& Mayer, J. D. (2003). Convergent, discriminant, and incremental validity of competing measures of emotional intelligence. Personality and Social Psychology Bulletin, 29, 1147-1158. doi: 10.1177/0146167203254596

Brackett, M. A., Mayer, J.D., Warner, R. (2004). Emotional intelligence and its relation to everyday behavior. Personality and Individual Differences, 36, 1387-1402. doi: 10.1016/S0191-8869(03)00236-8 
Chen, G., Gully, S. M., \& Eden, D. (2001). Validation of a new general self-efficacy scale. Organizational Research Methods, 4, 62-83. doi: 10.1177/109442810141004

Choo, L. S. \& Nasurdin, A. (2014). An empirical investigation into the influence of human resource management practices on work engagement: The case of customercontact employees in Malaysia. International Journal of Culture, 8, 345-360. doi: 10.1108/GM-11-2014-0105

Cole, M. S., Bruch, H., \& Vogel, B. (2006). Emotion as mediators of the relations between perceived supervisor support and psychological hardiness on employee cynicism. Journal of Organizational Behavior, 27, 463-484. doi: 10.1002/job.381

Cooper, A. \& Petrides, K. V. (2010). A psychometric analysis of the trait emotional intelligence questionnaire-short form (TEIQue-SF) using item response theory. Journal of Personality Assessment, 92, 449-457. doi: 10.1080/00223891.2010.497426

Crawford, E. R., LePine, J. A., \& Rich, B. L. (2010). Linking job demands and resources to employee engagement and burnout: A theoretical extension and meta-analytic test. Journal of Applied Psychology, 95, 834-848. doi: 10.1037/a0019364

Csikszentmihalyi, M. (1990). Flow: The psychology of optimal experience. Journal of Leisure Research, 24, 91-94. doi: 10.1080/00222216.1992.11969876

Deci, E. L. \& Ryan, R. M. (2000). Self determination theory and the facilitation of intrinsic motivation, social development, and well-being. American Psychologist, 55, 68-78. doi: 10.1037110003-066X.55.1.68

Deci, E. L. \& Ryan, R. M. (2008). Self-determination theory: A macrotheory of human motivation, development, and health. Canadian Psychology/Psychologie Canadienne, 49, 182-185. doi: 10.1037/a0012801

DeConinck, J. B. (2010). The effect of organizational justice, perceived organizational support, and perceived supervisor support on marketing employees' level of trust. Journal of Business Research, 63, 1349-1355. doi:10.1016/j.jbusres.2010.01.003

Eisenberger, R., Stinglhamber, F., Vandenberghe, C., Sucharski, I. L., \& Rhoades, L. (2002). Perceived supervisor support: Contributions to perceived organizational support and employee retention. Journal of Applied Psychology, 87, 565-573. doi: 10.1037/0021-9010.87.3.565

Hobfoll, S. E., Johnson, R. J., Ennis, N., \& Jackson, A. P. (2003). Resource loss, resource gain, and emotional outcomes among inner city women. Journal of Personality and Social Psychology, 84, 632-643. doi: 10.1037/0022-3514.84.3.632 
Gagne M., Bhave D. (2011) Autonomy in the workplace: An essential ingredient to employee engagement and wellbeing in every culture. In Chirkov V., Ryan R., Sheldon K. (Eds.), Human autonomy in cross-cultural context: Cross-cultural advancements in positive psychology (pp. 163-187). Berlin, Germany: Springer Science + Business Media.

Gagné, M. and Deci, E.L. (2005). Self-determination theory and work motivation. Journal of Organizational Behavior, 26, 331-362. doi: 10.1002/job.322

Gallagher, E. N. \& Vella-Brodrick, D. A. (2008). Social support and emotional intelligence as predictors of subjective well-being. Personality and Individual Differences, 44, 1551-1561.

Gallup, 2013. State of the Global Workplace: Employee Engagement Insights for Business Leaders Worldwide. Washington, DC: Gallup.

Hackman, J. R. \& Oldham, G. R. (1975). Development of the job diagnostic survey. Journal of Applied Psychology, 60, 159-170. doi: 10.1037/h0076546

Halbesleben, J. R. B. (2010). A meta-analysis of work engagement: Relationships with burnout, demands, resources, and consequences. In A. B. Bakker \& M. P. Leiter (Eds.), Work engagement: A handbook of essential theory and research (pp. 102117). New York, NY: Psychology Press.

Harms, P. D. \& Credé, M. (2010). Emotional intelligence and transformational and transactional leadership: A meta-analysis. Journal of Leadership \& Organizational Studies, 17, 5-17. doi: 10.1177/1548051809350894

Hobfoll, S. (2002). Social and psychological resources and adaptation. Review of General Psychology, 6, 307-324. doi: 10.1037/1089-2680.6.4.307

Johnson, S. J., Batey, M., \& Holdsworth, L. (2009). Personality and health: The mediating role of trait emotional intelligence and work locus of control. Personality and Individual Differences, 47, 470-475. doi: 10.1016/j.paid.2009.04.025

Joseph, D. L. \& Newman, D. A. (2010). Emotional intelligence: An integrative metaanalysis and cascading model. Journal of Applied Psychology, 95, 54-78. doi: $10.1037 / \mathrm{a} 0017286$

Kahn, W. A. (1990). Psychological conditions of personal engagement and disengagement at work. Academy of Management Journal, 33, 692-724. doi: $10.2307 / 256287$ 
Lee, J. \& Ok, C. (2012). Reducing burnout and enhancing job satisfaction: Critical role of hotel employees' emotional intelligence and emotional labor. International Journal of Hospitality Management, 31, 1101-1112. doi: 10.1016/j.jhm.2012.01.007

Lopes, P. N., Salovey, P., Straus, R. (2003). Emotional intelligence, personality, and the perceived quality of social relationships. Personality and Individual Differences, 35, 641-658. doi: 10.1016/S0191-8869(02)00242-8

Lopes, P. N., Brackett, M. A., Nezlek, J. B., Schutz, A., Sellin, I., Salovey, P. (2004). Emotional intelligence and social interaction. Personality and Social Psychology Bulletin, 30, 1018-1034. doi: 10.1177/0146167204264762

Macey, W. H., Schneider, B., Barbera, K. M., \& Young, S. A. (2009). Talent management essentials. Employee engagement: Tools for analysis, practice, and competitive advantage. Malden, MA: Wiley-Blackwell.

Makikangas, A. \& Kinnunen, U. (2003). Psychosocial work stressors and well-being: Self-esteem and optimism as moderators in a one-year longitudinal sample. Personality and Individual Differences, 35, 537-557. doi: 10.1016/S01918869(02)00217-9

Mars, G., Van Eijk, J., Post, M., Proot, I., Mesters, I., \& Kempen, G. (2014). Development and psychometric properties of the Maastricht Personal Autonomy Questionnaire (MPAQ) in older adults with a chronic physical illness. Quality of Life Research, 23, 1777-1787.

Martins, A., Ramalho, N., \& Morin, E. (2010). A comprehensive meta-analysis of the relationship between emotional intelligence and health. Personality and Individual Differences, 49, 554-564. doi:10.1016/j.2010.05.029

Maslach, C., \& Leiter, M.P. (1997). The truth about burnout. San Francisco, CA: JosseyBass.

Maslach, C., Schaufeli, W. B., \& Leiter, M. P. (2001). Job burnout. Annual Review of Psychology, 52, 397-422. doi:10.1146/annurev.psych.52.1.397

Mayer, J. D., \& Salovey, P. (1997). What is emotional intelligence? In P. Salovey \& D. J. Sluyter (Eds.), Emotional development and emotional intelligence: Educational implications (pp. 3-34). New York, NY: Basic Books.

Meijman, T. F., \& Mulder, G. (1998). Psychological aspects of workload. In P. J. D. Drenth, H. Thierry, \& C. J. de Wolff (Eds.), Handbook of work and organizational: Work psychology (pp. 5-33). Oxfordshire, United Kingdom: Psychology Press/Erlbaum Taylor \& Francis. 
O'Boyle, E. H., Jr., Humphrey, R. H., Pollack, J. M., Hawver, T. H. and Story, P.A. (2011). The relation between emotional intelligence and job performance: A metaanalysis. Journal of Organizational Behavior, 32, 788-818. doi:10.1002/job.714

Othman, N., \& Nasurdin, A. M. (2012). Social support and work engagement: A study of Malaysian nurses. Journal of Nursing Management, 21, 1083-1090. doi: $10.1111 /$ j.1365-2834.2012.01448.x

Petrides, K. V., \& Furnham, A. (2001). Trait emotional intelligence: psychometric investigation with reference to established trait taxonomies. European Journal of Personality, 15, 425-448. doi: 10.1002/per.416

Pierce, J. L., Gardner, D. G., Cummings, L. L., \& Dunham, R. B. (1989). Organizationbased self-esteem: Construct definition, operationalization, and validation. Academy of Management Journal, 32, 622-648. doi: 10.5465/256437

Pierce, J. L., \& Gardner, D. G. (2004). Self-esteem within the work and organizational context: A review of the organization-based self-esteem literature. Journal of Management, 30, 591-622. doi: 10.1016/j.jm.2003.10.001

Prati, G., Pietrantoni, L., \& Cicognani, E. (2010). Self-efficacy moderates the relationship between stress appraisal and quality of life among rescue workers. Anxiety, Stress \& Coping, 23, 463-470. doi: 10.1080/10615800903431699

Remo, Neli. (2012). Comparing two models of employee engagement: An examination of antecedents and outcome variables (Doctoral dissertation, University of Windsor, Canada). Retrieved from University of Windsor Electronic Theses and Dissertations.

Rhee, S. Y. \& Yoon, H. J. (2011). Shared Positive Affect in Workgroups. In K. S. Cmeron \& G. M. Sprietzer (Eds.), Handbook of positive organizational scholarship (pp. 215-227). Oxford, United Kingdom: Oxford University Press.

Saks, A. M. (2006). Antecedents and consequences of employee engagement. Journal of Managerial Psychology, 21, 600-619. doi: 10.1108/02683940610690169

Salovey, P., \& Mayer, J. D. (1989-1990). Emotional intelligence. Imagination, Cognition and Personality, 9, 185-211. doi: 10.2190/DUGG-P24E-52WK-6CDG

Schaufeli, W. B., \& Bakker, A. B. (2004). Job demands, job resources, and their relationship with burnout and engagement: A multi-sample study. Journal of Organizational Behavior, 25, 293-315. doi: 10.1002/job.248

Schaufeli, W. B., \& Bakker, A. B. (2010). Defining and measuring work engagement: 
Bringing clarity to the concept. In A. B. Bakker (Ed.) \& M. P. Leiter, Work engagement: A handbook of essential theory and research (pp. 10-24). Mortimer Street, London: Psychology Press.

Schaufeli, W. B., \& Salanova, M. (2007). Efficacy or inefficacy, thats the question: Burnout and work engagement, and their relationships with efficacy beliefs. Anxiety, Stress, \& Coping, 20, 177-196. doi: 10.1080/10615800701217878

Schaufeli, W. B., Salanova, M., González-Romá, V., \& Bakker, A. B. (2002). The measurement of engagement and burnout: A two sample confirmatory factor analytic approach. Journal of Happiness Studies, 3, 71-92. doi: 10.1023/A:1015630930326

Scheier, M. F., \& Carver, C. S. (1985). Optimism, coping, and health: Assessment and implications of generalized outcome expectancies. Health Psychology, 4, 219-247. doi: 10.1037/0278-6133.4.3.219

Sorenson, S. \& Garman, K. (2013). How to tackle U.S. employee's stagnating engagement, Gallup. Retrieved from https://news.gallup.com/businessjournal/162953/tackle-employees-stagnatingengagement.aspx

Schutte, N. S., \& Malouff, J. M. (2011). Emotional intelligence mediates the relationship between mindfulness and subjective well-being. Personality and Individual Differences, 50, 1116-1119. doi: 10.1016/j.paid.2011.01.037

Schutte, N. S., Malouff, J. M., \& Thorsteinsson, E. B. (2013). Increasing emotional intelligence through training: Current status and future directions. The International Journal of Emotional Education, 5, 56-72. Retrieved from http://sciamajor.com

Tharenou, P. (2001), The relationship of training motivation to participation in training and development. Journal of Occupational and Organizational Psychology, 74, 599621. doi:10.1348/096317901167541

Wang, G. \& Netemeyer, R. G. (2002). The effects of job autonomy, customer demandingness, and trait competitiveness on salesperson learning, self-efficacy, and performance. Journal of the Academy of Marketing Science, 30, 217-228. doi: $10.1177 / 00970302030003003$

White, R. W. (1959). Motivation reconsidered: The concept of competence. Psychological Review, 66, 297-333. doi: 10.1037/h0040934 
Wong, C. S., \& Law, K. S. (2002). The effects of leader and follower emotional intelligence on performance and attitude: An exploratory study. The Leadership Quarterly, 13, 243-274. doi: 10.1016/S1048-9843(02)00099-1

Xanthopoulou, D., Bakker, A. B., Demerouti, E., \& Schaufeli, W. B. (2007). The role of personal resources in the job demands-resources model. International Journal of Stress Management, 14, 121-141. doi: 10.1037/1072-5245.14.2.121 


\section{Appendix}

Demographic Questionnaire Items

1. Are you currently employed?

O Yes

O No

2. What is your current age?

Younger than 18 years old

O $18-24$ years old

O 25 - 34 years old

O 35 - 44 years old

O 45-54 years old

O 55-64 years old

O 65 years or older

3. What ethnicity do you identify most with?

O White/Caucasian

Hispanic or Latino/a

O Black/African American

O Native American or Alaska Native

O Asian or Pacific Islander

O Other

4. What gender do you identify with?

O Male

O Female

O Other

5. What is your employment status?

O Full time

O Part time

6. Which best describes the type of organization you work for?

For profit

Non-profit (religious, arts, social assistance, etc.)

O Government

O Health Care

O Education

Other 
7. What is your current job type?

O Individual Contributor (Full time employee)

O Manager (Full time Employee)

O Contractor

Other 


\section{Scale Items}

\section{Perceived Supervisor Support}

8. My manager fosters genuine and trusting relationships on the team.

9. My manager supports my overall success and achievement.

10. My manager supports my professional growth and development.

11. My manager helps me learn from my mistakes and turns them into productive development opportunities.

12. My manager routinely communicates with me so that I am able to perform and develop in my position.

13. My manager helps me get the resources that I need to do my job.

14. My manager models the company core values.

15. My manager gathers my input when making decisions that affect me.

16. My manager rewards me in a manner that makes me feel valued.

\section{Autonomy}

17. I am allowed to decide how to go about getting my job done (the methods to use).

18. I am able to choose the way to go about my job (the procedures to utilize).

19. I am free to choose the methods to use in carrying out my work.

20. I have some control over the sequencing of my work activities (when I do what).

21. My job is such that I can decide when to do particular work activities.

22. My job allows me to modify the normal way we are evaluated so that I can emphasize some aspects of my job and play down others.

23. I am able to modify what my job objectives are (what I am supposed to accomplish).

24. I have some control over what I am supposed to accomplish (what my supervisor sees as my job objectives).

\section{Emotional Intelligence}

25. Expressing my emotions with words is not a problem for me.

26. I often find it difficult to see things from another person's viewpoint.

27. On the whole, I'm a highly motivated person.

28. I usually find it difficult to regulate my emotions.

29. I generally don't find life enjoyable 
30. I can deal effectively with people.

31. I tend to change my mind frequently.

32. Many times, I can't figure out what emotion I'm feeling.

33. I feel that I have a number of good qualities.

34. I often find it difficult to stand up for my rights.

35. I'm usually able to influence the way other people feel.

36 . On the whole, I have a gloomy perspective on most things.

37. Those close to me often complain that I don't treat them right.

38. I often find it difficult to adjust my life according to the circumstances.

39. On the whole, I'm able to deal with stress.

40. I often find it difficult to show my affection to those close to me.

41. I'm normally able to "get into someone's shoes" and experience their emotions.

42. I normally find it difficult to keep myself motivated.

43. I'm usually able to find ways to control my emotions when I want to.

44. On the whole, I'm pleased with my life.

45. I would describe myself as a good negotiator.

46. I tend to get involved in things I later wish I could get out of.

47. I often pause and think about my feelings.

48. I believe I'm full of personal strengths.

49. I tend to "back down" even if I know I'm right.

50. I don't seem to have any power at all over other people's feelings.

51. I generally believe that things will work out fine in my life.

52. I find it difficult to bond well enough with those close to me.

53. Generally, I'm able to adapt to new environments.

54. Others admire me for being relaxed.

\section{Engagement}

55. At work I feel like bursting with energy.

56. At my job I feel strong and vigorous.

57. When I get up in the morning, I feel like going to work.

58. I can continue to work for long periods of time. 
59. At my job, I am mentally resilient.

60. At my job, I always persevere, even when things do not go well.

61. I find the work that I do meaningful and purposeful.

62. I am enthusiastic about my job.

63. My job inspires me.

64. I am proud of the work that I do.

65 . My job is challenging enough.

66. Time flies when I am at work.

67. When I work, I forget everything else around me.

68. I feel happy when I work intensively.

69. I am immersed in my work.

70. I get carried away when I work.

71. It is difficult to detach myself from my job. 